\title{
Electron Flux and Cosmic Ray Anomaly Before H1N1 Outbreak
}

\section{Mukherjee S}

School of Environmental Sciences, Jawaharlal Nehru University, New Delhi-110067, India

*Corresponding author: Mukherjee S, School of Environmental Sciences, Jawaharlal Nehru University, New Delhi-110067, India, Tel: 0091-11-261876; E mail: saumitramukherjee3@gmail.com

Rec date: Jun 13, 2014; Acc date: Jul 03, 2014; Pub date: Jul 10, 2014

Copyright: $\odot 2014$ Mukherjee S. This is an open-access article distributed under the terms of the Creative Commons Attribution License, which permits unrestricted use, distribution, and reproduction in any medium, provided the original author and source are credited.

\begin{abstract}
Climate change manifestations are not only observed as vanishing glaciers, erratic rainfall sudden rise in temperature but disease outbreak also. Space weather environment study has been attempted to infer the H1N1 early warning. Continuous low electron flux anomaly has been observed before the occurrence of the H1N1 pandemics in Mexico in March 2009.The anomaly was recorded by Sun Observatory Heliospheric Observatory an extra-terrestrial satellite of NASA. During the period of low electron flux anomalous rise in the cosmic ray intensity has been recorded locally in Mexico City cosmic ray observatory. This paper shows preliminary evidence of possible early warning of influenza by using remotely sensed data from satellite as a manifestation of climate change.
\end{abstract}

Keywords: Cosmic ray; Early warning; Electron flux; H1N1; Space weather

\section{Introduction}

Influence of Sun and extragalactic cosmic rays on the environment of the earth [1-2] is under active consideration within scientific community. A correlation is being attempted to establish in between triggering of $\mathrm{H} 1 \mathrm{~N} 1$ pandemics [3-4] with a continuous low electron flux from the Sun and locally high cosmic rays during unexpected solar minimum [5-7] of 2009. The mutation of viruses are difficult to predict in space and time [8]. The hypothesis is based on the mutation in the body cells of human being or the active virus in the air in Mexico during last week of February 2009 to first week of March 2009 followed by the attack of the virus. Subsequently the influenza virus has further mutated due to heavy shower of cosmic rays and low electron flux [9].

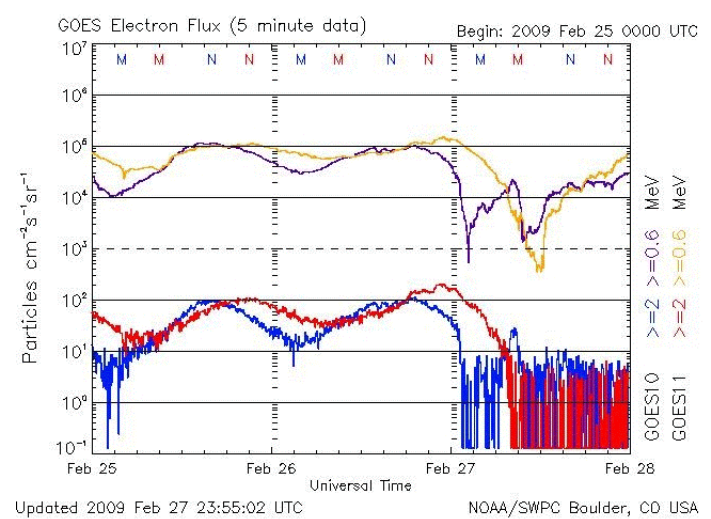

Figure 1: Sudden fall in Electron flux on $27^{\text {th }}$ February 2009 recorded by SOHO satellite data

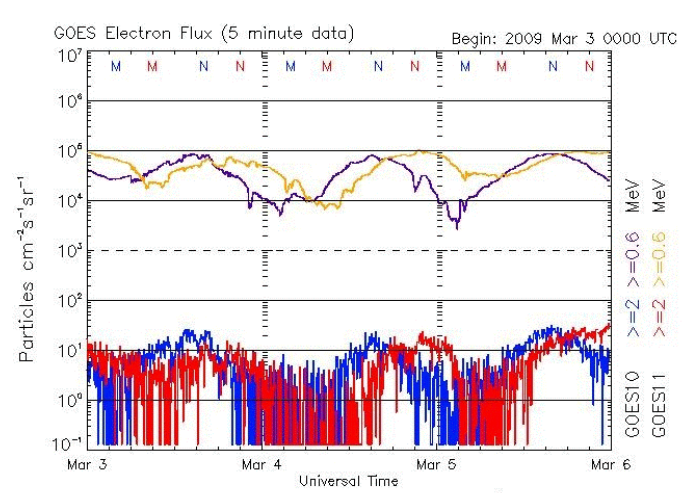

Updated 2009 Mar 5 23:55:02 UTC Universal Time NOAA/SWPC Boulder, CO USA

Figure 2: Low Electron flux from $3^{\text {rd }}$ March to $6^{\text {th }}$ March 2009 recorded by $\mathrm{SOHO}$ satellite data

Global pandemics of H1N1 influenza are currently being observed, and future scenario suggests limited possibility to develop an early warning of any type of influenza [10-11]. The earth and its environment are continuously being showered with cosmic rays from the Sun and outer space [12]. Cosmic rays affect many aspects of our lives, and sometimes these small particles can create significant problems. Cosmic rays are potential to change a chromosome in a reproductive cell [13]. After colliding with the atmospheric gases the cosmic rays generates secondary particles. Secondary cosmic rays spread out and continue to hit other particles and air molecules which further produce cascade of particles showering towards the ground. Secondary cosmic rays produced from the primary cosmic rays may have iron [14] or other transition elements in its nucleolus which enables them to reach faster on earth. Cosmic ray monitors record short term variations as well as long term cycles [15] which coincide with the H1N1 pandemics. Mutations, or disruption of the DNA replication process, may be caused by a number of agents, including 
radiation, of which muons are one type. At the earth's surface, muons are relatively rare compared to natural radiation in the body or other environmental sources.

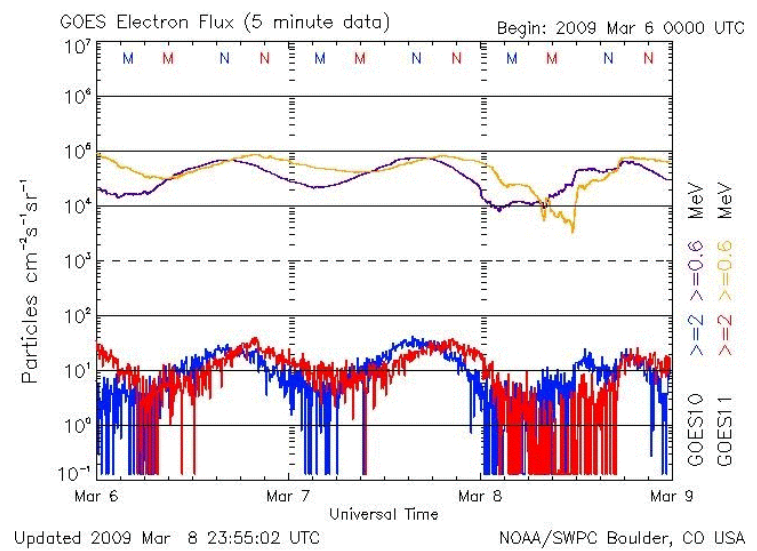

Figure 3: Low Electron flux from $6^{\text {th }}$ March to $9^{\text {th }}$ March 2009 recorded by $\mathrm{SOHO}$ satellite data

Also, there are bio-agents viruses which impart their DNA into host cells. Scientists are working to answer this question and to understand how solar activity and cosmic rays might affect conditions on Earth's surface [16].

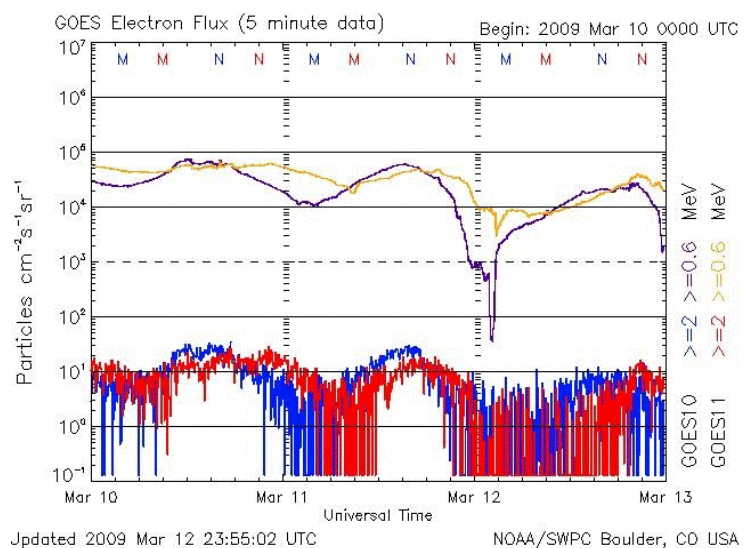

Figure 4: Low Electron flux from $10^{\text {th }}$ March to $13^{\text {th }}$ March 2009 recorded by SOHO satellite data

There was a period between the years 1645 and 1715 , called the Maunder Minimum, when there was little solar activity and few sunspots. During the same time it was a period called the Little Ice Age when temperatures became cooler in North America and Europe.It has been recorded that during the low activity of Sun, very few or no sunspot were visible in the Sun.

Cosmic ray intensity has been recorded higher during no sunspot activity [17]. In 1971, Nature magazine published the research of R.E. Hope-Simpson, which showed that sunspot cycles correlate with influenza pandemics associated with antigenic shifts (any substance that can stimulate the production of antibodies) in the virus; the virus mutated to a different variety with each successive sunspot cycle, showing that the sun's radiation can disrupt replication of a virus. Cosmic rays are potential to mutate the living cells [18] which come in its contact. Genetic mutations are always not harmful but sometimes it can change the susceptibility of the human cells prone to the H1N1 Virus attack. Between March and August of 2009 millions of patients across the world have shown severe influenza-like symptoms and respiratory failure.

Sun Observatory and Heliospheric Observatory (SOHO) satellite has recorded unusually low electron flux (Eflux) from $27^{\text {th }}$ February to $13^{\text {th }}$ March 2009 (Figures 1-5).

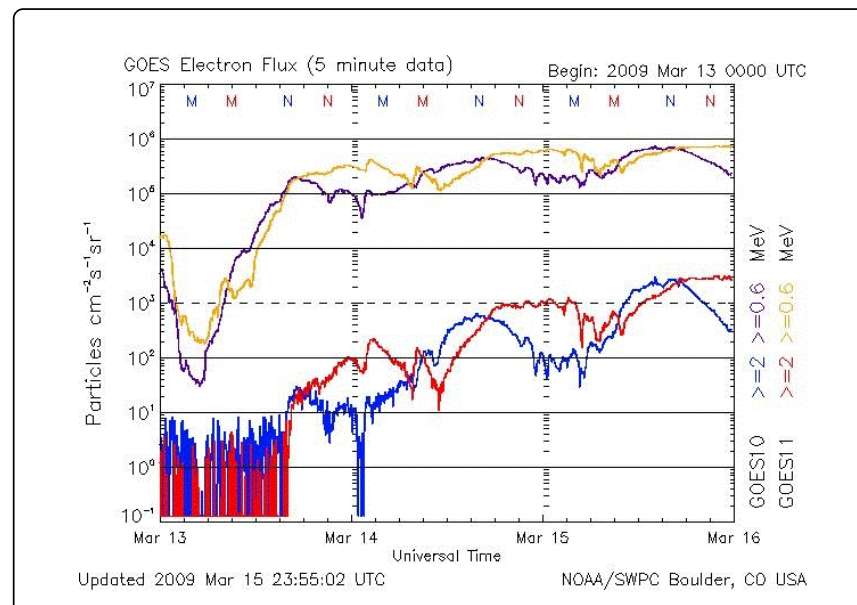

Figure 5: Persistent Low Electron flux show sudden rise at afternoon of $13^{\text {th }}$ March 2009 recorded by SOHO satellite data

A dip in cosmic ray intensity has also been recorded on $27^{\text {th }}$ February 2009 (Figure 6).

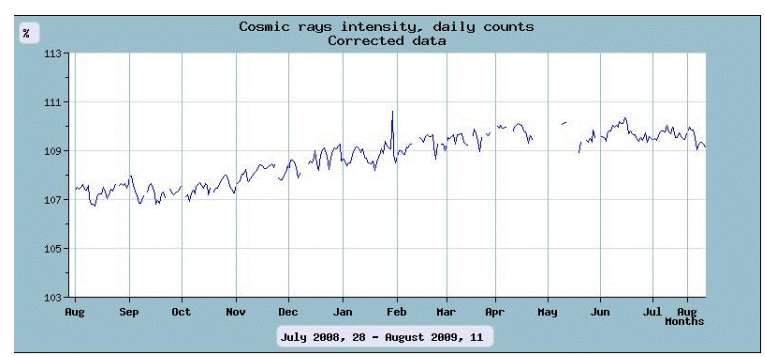

Figure 6: Cosmic ray intensity shows a sudden peak on $27^{\text {th }}$ February 2009 recorded by Mexico City Cosmic ray observatory

Reportedly the Swine flu (H1N1) has started in 2009 from Mexico on $3^{\text {rd }}$ March 2009. Once the cosmic ray intensity increases locally it has the potential to mutate the skin cells of human being to make it vulnerable for the H1N1 viral infection. The triggering of H1N1 in human has spread very fast [19] and the virus further mutated itself to make it a pandemic disease.

SOHO satellite data is available for downloading [20], which can provide valuable information of sudden lowering of the electron flux. It is essential to monitor the whole earth by the cosmic ray detector [21]. 
Citation: Mukherjee S (2014) Electron Flux and Cosmic Ray Anomaly Before H1N1 Outbreak. J Climatol Weather Forecasting 2: 113. doi:

Page 3 of 3

It has been recorded that the cosmic ray intensity increased suddenly with a lowering of the Eflux before the H1N1 outbreak. It has been treated an early warning in the winter of 2010-2011 across the world. On $26^{\text {th }}$ April 2011, an H1N1 pandemic preparedness alert was issued by the World Health Organization for the Americas including Mexico [22].The whole world community can be saved in future from the fatal H1N1 viral influenza by taking suitable precaution during those days of low electron flux and high cosmic ray density.

\section{Acknowledgement}

I thank NASA, USA for providing the SOHO satellite data. Cosmic Ray data downloaded from the Mexico City Cosmic Ray observatory is duly acknowledged.

\section{References}

1. Mukherjee S (2008) Cosmic Influence on Sun-Earth Environment. Sensors 8: 7736-7752.

2. Curtis T (2004) How a Killer Virus Emerged: Changed Environment + Mutation $=$ Evolution.

3. Han K, Zhu X, He F, Liu L, Zhang L, et al. (2009) Lack of airborne transmission during outbreak of pandemic (H1N1) among tour group members. China. Emerg Infect Dis.

4. Wolfe ND, Dunavan CP, Diamond J (2007) Origins of major human infectious diseases. Nature 447: 279-283.

5. Scime EE, Littleton JE, Gary SP, Skoug R, Lin N (2001) Solar cycle variations in the electron heat flux: Ulysses observation. Geophys res let 28: 2169-2172.

6. Peiris JS, Poon LL, Guan Y (2009) Emergence of a novel swine-origin influenza A virus (S-OIV) H1N1 virus in humans. J Clin Viro 45: 169-173.
7. Ferguson NM, Anderson RM (2002) Predicting evolutionary changes in the influenza A virus. NatureMedicine 8: 562-563.

8. Timeline: Swine flu (2009) A chronology of the H1N1 outbreak. Nature.

9. YU ZD (1985) Using the information of cosmic rays to predict influence epidemic. 19th International Cosmic Ray Conference,5: 525-528

10. Serfling RE (1963) Methods for current statistical analysis of excess pneumonia-influenza deaths. Public Health Rep 78: 494-506.

11. World Health Organization (2005) Responding to the avian influenza pandemic threat. Recommended strategic actions.

12. Jokipii JR, McDonald FB (1995) Quest for the Limits of the Heliosphere. Scientific American 272: 58-63.

13. Rieseberg LH, Livingstone K (2003) Chromosomal Speciation in Primates. Science 300: 267-268.

14. Bengamasco L, Piazzoli BD, Mannocchi G (1980) The composition of primary cosmic rays near $107 \mathrm{GeV}$ from multiple underground muons. Lettere Al Nuovo Cimento 27: 71-74.

15. Gonzalez G (2009) Examining SORCE data shows the Sun continues its slide toward somnolence.

16. Friis-Christensen E, Lassen K (1991) Length of the solar cycle: an indicator of solar activity closely associated with climate. Science 254 : 698-700.

17. Mishra RK, Mishra RA (2008) Short-term variation of cosmic ray diurnal anisotropy and solar activity. Cosmic Research 46: 94-96.

18. Rosendahl IM, Baumstark-Khana C, Rinkb H (2005) Mutation induction in mammalian cells by accelerated heavy ions. Advances in Space Research 36: 1701-1709.

19. Shekhar C (2009) Pandemic Paradox: New Flu Virus Keeps Researchers and Health Officials Guessing. Chemistry \& Biology 16: 687-688.

20. http://sohowww.nascom.nasa.gov/

21. http://www.cosmicrays.unam.mx/

22. Worls Health Organization (2011) Issues H1N1 Pandemic Alert. 